\title{
Four Hypotheses to Explain Axillary Budbreak after Removal of Flower Shoots in a Cut-rose Crop
}

\author{
A. Maaike Wubs ${ }^{1}$ \\ Horticultural Supply Chains, Wageningen University, P.O. Box 630, 6700 AP Wageningen, \\ the Netherlands; and Centre for Crop Systems Analysis, P.O. Box 430, 6700 AK Wageningen, \\ The Netherlands \\ Ep Heuvelink ${ }^{3}$ \\ Horticultural Supply Chains, Wageningen University, P.O. Box 630, 6700 AP Wageningen, \\ The Netherlands \\ Leo F.M. Marcelis \\ Wageningen UR Greenhouse Horticulture, P.O. Box 644, 6700 AP Wageningen, The Netherlands; \\ and Horticultural Supply Chains, Wageningen University, P.O. Box 630, 6700 AP Wageningen, \\ The Netherlands \\ Robert C.O. Okello and Alisa Shlyuykova \\ Horticultural Supply Chains, Wageningen University, P.O. Box 630, 6700 AP Wageningen, \\ the Netherlands; and Centre for Crop Systems Analysis, P.O. Box 430, 6700 AK Wageningen, \\ The Netherlands \\ Gerhard H. Buck-Sorlin ${ }^{2}$ and Jan Vos \\ Centre for Crop Systems Analysis, P.O. Box 430, 6700 AK Wageningen, The Netherlands
}

Additional INDEX words. Rosa $\times$ hybrida, competing shoots, assimilate supply, plant architecture, light intensity, red:far-red ratio

\begin{abstract}
When flower-bearing shoots in cut-rose (Rosa $\times$ hybrida) are harvested (removed), a varying number of repressed axillary buds on the shoot remainder start to grow into new shoots (budbreak). Besides removing withinshoot correlative inhibition, it is hypothesized that shoot removal leads to 1) increased light intensity lower in the crop canopy; 2) changes in the light spectrum (particularly red:far-red ratio); and 3) changed source:sink ratio (i.e., the ratio between supply and demand of assimilates). As a fourth hypothesis it is proposed that the degree of budbreak on a shoot remainder is also influenced by the correlative inhibition exerted by other shoots on the plant. It is the goal of this work to determine which of these four hypotheses is most important for budbreak in a cut-rose crop. Four experiments were conducted, in which these factors were varied by leaf removal, removal of mature shoots, varying the number of young shoots, shading of the crop, and application of direct light on the buds. Increase in source:sink ratio was not consistently associated with higher budbreak. If source:sink ratio was decreased by removal of leaves or a mature shoot, budbreak showed even a tendency to increase. Budbreak was subject to correlative inhibition exerted by other shoots on the plant. Treatments where more light reached the bud (as a result of less shoots, no shading of the crop, application of local light) increased budbreak. Increased red:farred ratio had the same result as more light reaching the bud but was often interrelated with light intensity. It was concluded that after removal of the flower-bearing shoot, among the factors tested, light intensity on the buds was an important and consistent factor explaining budbreak on the shoot remainder, whereas the effect of light spectrum should be further investigated.
\end{abstract}

Received for publication 15 Feb. 2013. Accepted for publication 3 June 2013. This research was supported by the Dutch Technology Foundation STW-NWO (project 07435), which is the Technology Programme of the Ministry of Economic Affairs, and by the Product Board for Horticulture (project PT 13098).

We thank Jos Kanne, Gerard Brouwer, Theo Damen, Joke Oosterkamp, and Ans Hofman for their assistance in the experiments. We are grateful to the personnel of Unifarm for managing the plants and the climate. Members of the STW users committee are thanked for their advice about crop management.

${ }^{1}$ Current address: Biometris, Wageningen University and Research Centre, P.O. Box 100, 6700 AC Wageningen, The Netherlands.

${ }^{2}$ Current address: Institute National d'Horticulture et de Paysage, AGROCAMPUS OUEST Centre d'Angers, 2 rue André Le Nôtre, 49045 Angers cedex 01, France.

${ }^{3}$ Corresponding author. E-mail: ep.heuvelink@wur.nl.
Plant architecture comprises the type and relative arrangement of organs (Barthélémy and Caraglio, 2007). In a cut-rose crop, architecture of the crop is often modified by crop management. The primary shoot and, later during cultivation, shoots without flowers are bent to create an additional source of assimilate supply for growth (De Hoog, 2001). Mature shoots (close to flowering) are harvested periodically, leaving a shoot remainder of one or two nodes. This results in outgrowth of the axillary buds on the shoot remainder, generating new shoots, which constitute the next harvest. Before a shoot is harvested, the axillary buds on the lower part of the shoot do not grow out because signals from the shoot above it inhibit their growth. Such signals from plant parts inhibiting bud growth are called correlative inhibition (Zieslin and Halevy, 1976), of which 
apical dominance (i.e., inhibition that can be shown to be directly related to apical signal production) is an important, but not exclusive, component: in decapitated shoots, the length of the stem or the presence or absence of leaves and axillary buds was shown to affect the degree of breaking of lower-positioned buds (Zieslin and Halevy, 1976). Harvesting a mature shoot removes inhibition of the buds on the shoot remainder, exerted by the removed acropetal parts. It has been shown that the degree of breaking of buds on a shoot remainder depends on bud position; i.e., the degree of breaking generally declines in basipetal direction from the cut (e.g., Zieslin and Halevy, 1976). Furthermore, the degree of budbreak on a shoot remainder is hypothesized to depend on the changes that shoot removal itself brings about in the conditions of the shoot remainder. Besides removing within-shoot correlative inhibition, shoot removal leads to 1) increased light intensity lower in the crop canopy; 2) changes in the light spectrum (higher intensity of red light compared with far-red light, resulting in a higher red:far-red ratio); and 3) changed source:sink ratio (i.e., the ratio between supply and demand of assimilates). Lastly we hypothesize that the degree of budbreak on a shoot remainder is also influenced by the correlative inhibition from other shoots on the plant.

The effects of light intensity and light spectrum on budbreak have been intensively studied in model plants like Arabidopsis (Arabidopsis thaliana) and pea (Pisum sativum). In simple rose explants, percentage budbreak increased with increase in light intensities up to $200 \mu \mathrm{mol} \cdot \mathrm{m}^{-2} \cdot \mathrm{s}^{-1}$ (Girault et al., 2008). Complete darkness inhibited budbreak and interestingly, Girault et al. (2008) observed that the bud itself and not the stem was the active site for light perception in budbreak.

Mor and Halevy (1984) concluded that exposure to higher light levels increased budbreak of the top three nodes on a shoot remainder compared with more-shaded conditions. A methodological objection to this study is that the "high light environment" shoots were shoots protruding from the canopy, whereas the "shaded treatment" shoots were in the canopy. Both types of shoots were located in different positions on the plant, so confounding of treatment and positional effect cannot be excluded. The fact that higher amounts of light (e.g., higher daily light integrals resulting from assimilation lights) incident on the crop results in more flower shoots (Kosh-Khui and George, 1977) is no critical evidence for an effect of light intensity on budbreak, because light is likely to influence the fraction of broken buds that finally produces a harvestable flower (Zieslin and Mor, 1990). More shoots resulting from higher light intensities were also reported for Vaccinium bracteatum (Kawamura and Takeda, 2002) and Macadamia integrifolia (Olesen et al., 2011).

Light spectrum affected budbreak in rose explants: far-red light-emitting diodes (LEDs) inhibited budbreak, whereas red, blue, and white light promoted budbreak (Girault et al., 2008). When whole rose plants were illuminated with higher red:farred ratios, more buds sprouted than when illuminated with light of a red:far red ratio of 0.64 (Mor and Halevy, 1984; Mor et al., 1980; Zieslin and Mor, 1990). Similar reports exist for species other than rose. Both higher red:far-red ratio and higher light intensity increased tiller production in Triticum aestivum (Evers et al., 2006), shoot production in Salvia exserta (Mata and Botto, 2011), and budbreak in wild-type Arabidopsis (Finlayson et al., 2010; Su et al., 2011). However, in most work regarding the effect of light intensity and light spectrum on budbreak, the light on the whole crop is changed, whereas the effect might be different when only the light intensity and/or spectrum on the bud itself is considered.

Harvest of rose shoots alters the source:sink ratio of the plant as well. Whether this affects budbreak is less well known. More lateral buds developed in chrysanthemum (Dendranthema $\times$ grandiflorum) under high light intensities. This was attributed to higher assimilation rates (Schoellhorn et al., 1996) and thus higher availability of assimilates (source strength). Henry et al. (2011) demonstrated that buds are sink organs, which need to import sugars for proper development. The uptake of sugars by buds coincides with the onset of budbreak (Maurel et al., 2004). Young rose shoots (before appearance of the flower bud) act as sinks (Mor and Halevy, 1979). The presence of young rose shoots, therefore, decreases the availability of assimilates for buds and the source:sink ratio of the plant and might inhibit budbreak in this way. Shoots from which the flower bud is just visible ( 2 to $5 \mathrm{~mm}$ ) have enough capacity to sustain themselves without assimilate import from other plant parts (Mor and Halevy, 1979) and will increase the source:sink ratio.

Research regarding budbreak has often focused on one aspect, keeping other aspects constant. However, the relative importance of the factors outlined previously and their possible interactions in an established crop is less well known. Taking into account the existing literature on axillary budbreak in rose, we designed a series of experiments aiming to determine the relative importance of four hypotheses for regulation of budbreak in response to shoot removal in a cut-rose crop: 1) light intensity received by the bud; 2) light spectrum received by the bud; 3) correlative inhibition exerted by plant components other than the shoot itself; and 4) source:sink ratio.

The current study adds to existing knowledge for the following reasons: 1) we used a cultivation system as commonly used in practice, including decapitation leaving approximately two nodes on the shoot remainder; 2) we studied the responses of buds in the context of a whole plant; and 3) we varied the light environment at the level of the bud and not at the level of the canopy. Lastly, we also examined the change in fraction budbreak over time (Bredmose, 1997) because these temporal patterns are very important from a practical point of view.

\section{Materials and Methods}

General information. Experiments were carried out in a rose crop (cv. Akito). The crop was grown in a $12 \times 12-\mathrm{m}^{2}$ compartment of a multispan Venlo-type greenhouse in Wageningen, The Netherlands (lat. $52^{\circ} \mathrm{N}$ ). The crop was established early in 2008 from one-node cuttings bearing a shoot. Cuttings were inserted in rockwool cubes $(7 \times 7 \times 7 \mathrm{~cm}$, Grodan delta; Grodan, Roermond, The Netherlands), which were placed onto rockwool slabs (Grodan). Plants were placed in double rows ( $0.25 \mathrm{~m}$ apart) with a distance of $0.20 \mathrm{~m}$ within the rows, resulting in a planting density of 6.5 plants $/ \mathrm{m}^{2}$. The shoot of the cutting was bent below the horizontal line and kept in place with wire. This so-called bent shoot is common practice in commercial cut-rose cultivation and increases assimilate production in the plants (De Hoog, 2001). From the base of the bent shoot, two buds were allowed to grow (bottom breaks); others were removed at an early stage. At maturity (shoots bearing open flower), all shoots resulting from these buds were harvested two or three nodes above their base. This was the first so-called "flush" of harvested shoots. On the shoot remainders of these harvested shoots, buds started to grow and were pruned to four 
shoots per plant, forming the second flush of shoots. These were the shoots used in the first experiment. After the first experiment, an underhook cut was applied (Zieslin, 1981), in which the shoots bearing a flower were cut below their base. After this, two flushes were grown, called reset flushes. A reset flush was the period in which the crop could recover from the treatments, the bent shoot could be restored (if necessary), and plants that underwent different treatments were allowed to recover to the same shape and size. After the reset flushes, the second experiment was conducted. Between the second and third experiments, another two reset flushes were grown. The last experiment was conducted after several other experiments and reset flushes. Experiments comprised half of the rows in the greenhouse; the other half of the rows was used for other experiments or undergoing reset flushes.

Supplemental light was provided by high-pressure sodium lamps (600 W; Philips, Eindhoven, The Netherlands) which provided a photosynthetically active radiation $(P A R)$ of 150 $\mu \mathrm{mol} \cdot \mathrm{m}^{-2} \cdot \mathrm{s}^{-1}$ at crop level. Supplemental light was provided between 0000 and 2000 HR (until 15 Dec. 2009) or between 0000 and $1800 \mathrm{HR}$ (since 15 Dec. 2009) when global radiation was below $150 \mathrm{~W} \cdot \mathrm{m}^{-2}$ outside the greenhouse $\left(\approx 318 \mu \mathrm{mol} \cdot \mathrm{m}^{-2} \cdot \mathrm{s}^{-1}\right.$ $P A R$ depending on light spectrum) and switched off when this radiation exceeded $250 \mathrm{~W} \cdot \mathrm{m}^{-2}\left(\approx 530 \mu \mathrm{mol} \cdot \mathrm{m}^{-2} \cdot \mathrm{s}^{-1} P A R\right.$ depending on light spectrum). Heating set points were $17.5^{\circ} \mathrm{C}$ during the night and $21.0{ }^{\circ} \mathrm{C}$ during the day. Realized climate conditions per experiment are given in Table 1. Water and nutrients $\left(0.17 \mathrm{~g} \cdot \mathrm{L}^{-1}\right.$ nitrogen, $0.04 \mathrm{~g} \cdot \mathrm{L}^{-1}$ phosphorus, $0.18 \mathrm{~g} \cdot \mathrm{L}^{-1}$ potassium, Substrafeed E1; Yara Benelux, Vlaardingen, The Netherlands) were supplied through a drip system (one dripper per plant).

Four experiments were carried out and described in detail below. In each experiment, bud outgrowth was observed on a shoot remainder of two nodes resulting from the harvest of a mature shoot. The shoot remainder had three positions for axillary budbreak: the upper node (x1), the lower node (x2), and the basal ring ( $\mathrm{r}$ ), where the shoot was attached to the lower order branch. At the position in the ring, more than one bud could grow. Buds with a length of $1.5 \mathrm{~cm}$ were considered as broken, and the date when a bud reached $1.5 \mathrm{~cm}$ was considered as the day of budbreak.

Expt. 1: Different number of young Shoots. In this experiment, the effect of the number of young growing shoots on bud outgrowth was observed. Treatments were 1) no young shoots per plant; 2) one young shoot per plant; 3) two young shoots per plant; 4) three young shoots per plant; and 4) four young shoots per plant. These young shoots acted as sinks for

Table 1. Climatic variable in the four experiments: $24-\mathrm{h}$ means for radiation, air temperature, relative humidity, and $\mathrm{CO}_{2}$ inside the greenhouse.

\begin{tabular}{lcccc}
\hline $\begin{array}{l}\text { Expt. } \\
\text { no. }\end{array}$ & $\begin{array}{c}\text { Radiation } \\
\left(\mu \mathrm{mol} \cdot \mathrm{m}^{-2} \cdot \mathrm{s}^{-1}\right)\end{array}$ & $\begin{array}{c}\text { Air temp } \\
\left({ }^{\circ} \mathrm{C}\right)\end{array}$ & $\begin{array}{c}\text { Relative } \\
\text { humidity }(\%)\end{array}$ & $\begin{array}{c}\mathrm{CO}_{2} \\
\left(\mu \mathrm{mol} \cdot \mathrm{mol}^{-1}\right)\end{array}$ \\
\cline { 2 - 5 }$(\mathrm{mean} \pm \mathrm{SD})$ \\
2 & NA & $23.1 \pm 1.69$ & $67.8 \pm 4.90$ & $441 \pm 16.1$ \\
3 & $132 \pm 12.3$ & $19.8 \pm 0.54$ & $72.7 \pm 2.69$ & $490 \pm 13.0$ \\
$4 \mathrm{a}$ & $235 \pm 41.6$ & $21.5 \pm 0.83$ & $63.0 \pm 4.94$ & $461 \pm 15.1$ \\
$4 \mathrm{~b}$ & $160 \pm 10.9$ & $19.2 \pm 0.56$ & $77.8 \pm 3.32$ & $461 \pm 10.7$ \\
\hline
\end{tabular}

$\mathrm{NA}=$ data not available. assimilates. The experiment started with plants where four shoots were present (see description previously). Approximately 2 weeks before they would normally be harvested, three shoots were cut two nodes above their base. There was one shoot remaining ( $\mathrm{X}$ in Fig. 1A). Date of budbreak on the shoot remainders from the harvested shoots was recorded for all buds. The shoot resulting from the uppermost bud was termed the "GR1 shoot." Two weeks later, the remaining shoot (X in Fig. 1A) was harvested two nodes above its base. At the same time, young shoots resulting from bud outgrowth on the shoot remainders of the three shoots harvested previously were thinned to zero, one, two, three, or four shoots per plant (Fig. 1A). The

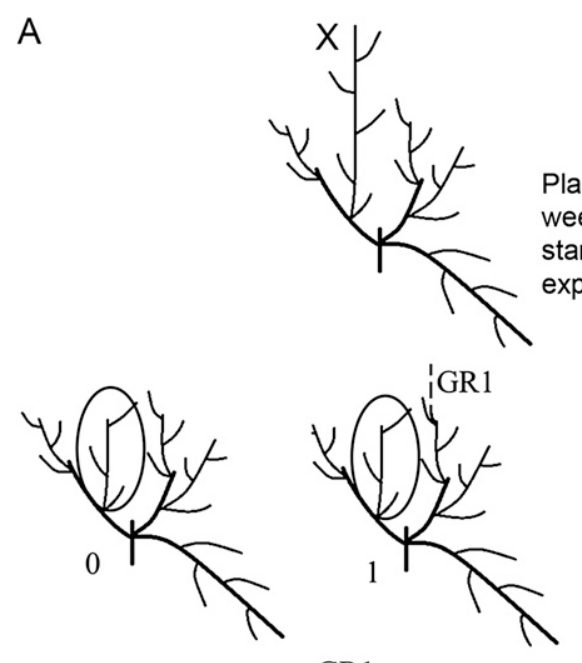

Plant 2 weeks before start of the experiment
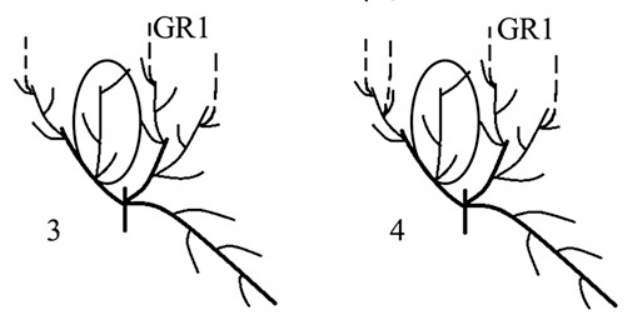

B
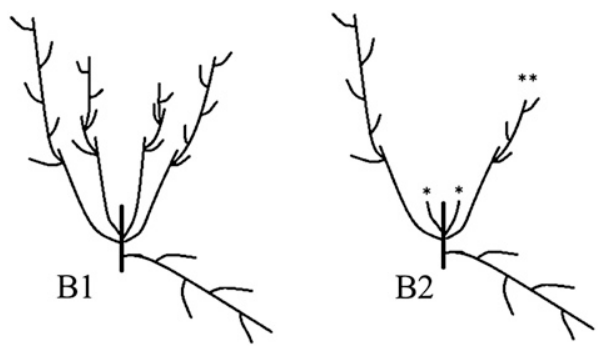

Fig. 1. Plant architectures of cut-rose in (A) the experiment with different numbers of young shoots per plant (Expt. 1) and (B) the experiment on the role of the bent shoot (Expt. 2). (A) Plant architecture at 2 weeks before the experiment started showing the bent shoot, three shoots cut back to two nodes above their base, and the remaining intact shoot $(\mathrm{X})$. Other drawings in A show the shoot remainder of the harvested shoot on which bud outgrowth was observed (encircled) on plants with zero, one, two, three, or four young growing shoots (young shoots depicted with broken line). GR1 indicates the shoot present in plants with one or more young shoots, of which growth was measured non-destructively over time. (B) Plants before the start of the experiment (B1) and plants from which the two inner shoots were removed with an underhook cut and one of the other shoots harvested (B2). Bud outgrowth was observed on the shoot remainders of the two lower parent shoots resulting from the underhook cut (indicated by *) and on the shoot remainder of the upper parent shoot resulting from harvest of a shoot (indicated by **). 
GR1 shoot was left growing in each treatment except for the treatment where no shoots were present. Bud outgrowth on the shoot remainder from the last harvested shoot $\mathrm{X}$ was observed for $21 \mathrm{~d}$ at least three times per week. Buds growing in other positions were removed twice per week.

According to Marcelis (1996), the growth rate of an organ $\left(G R_{i}\right)$ is the product of source strength (source) and the ratio between sink strength of the organ $\left(S_{i}\right)$ divided by that of the total plant $(\Sigma S)$ [Eq. (1)]. Sink strength was defined as the potential growth rate, which is the growth rate when assimilates are not limiting growth.

$$
G R_{i}=\text { source } \mathrm{x} S_{i} / \sum S
$$

Hence, the source:sink ratio (source / $\Sigma$ S) can be calculated as

$$
\text { source } / \sum S=G R_{i} / S_{i}
$$

As a relative indicator of the source:sink ratio, the growth of the GR1 shoot in each treatment was compared with the potential growth of a GR1 shoot $\left(S_{i}\right)$. Potential growth of the GR1 shoot was measured in an additional treatment $P$, where only the GR1 shoot was allowed to grow to create non-limiting assimilate supply. All other growing buds in this treatment were removed. Here we assume no treatment effect on sink strength. Growth of the GR1 shoot was measured non-destructively every week in half of the plants in each plot of each treatment (except for 0S where the GR1 shoot was not present) by measuring the length of the stem and the diameter at the stem base. From the other plants in each treatment, each week two to three GR1 shoots per plot were destructively measured; their stem length and diameter, fresh and dry weight of stem and leaves, and, if present, fresh and dry weight and diameter of the flower bud were measured. From these destructive measurements, relationships were derived to estimate total dry mass of the GR1 shoot.

The experiment was set up as a completely randomized design with two plots per treatment. A plot consisted of a double row with nine to 10 plants per row with two border plants at either side of the plot. The experiment was conducted in June and July 2008.

EXPT. 2: Role OF THE BENT SHOOT. In this experiment, the effect of assimilate supply from the bent shoot on bud outgrowth was studied. Four treatments were applied: 1) bent shoot cut off; 2) early shading of the bent shoot, 1 week before Treatments 1 and 3 were initiated; 3) late shading of the bent shoot; and 4) control, no treatment on the bent shoot.

Treatments 1 and 3 started at the same time, when also shoot remainders for observation of bud outgrowth were created. Bent shoots were cut off at their base, so no remainder of these shoots was present.

In the reset flush before the experiment, four shoots were kept per plant. Three weeks after harvest of the previous reset flush, two of the four shoots were cut back to $15 \mathrm{~cm}$ from the surface of the rockwool cube. Shoots sprouting from those shoot remainders were non-uniform (Fig. 1-B1). An underhook cut was applied to remove these shoots (Fig. 1-B2) and at the same time, one of the two remaining shoots was harvested, leaving a shoot remainder of two nodes. The other shoot was kept intact. Bud outgrowth was observed for $23 \mathrm{~d}$ on the shoot remainder resulting from harvest of the shoot (upper parent shoot) and on the two shoot remainders from the underhook cut (lower parent shoots) (Fig. 1-B2). Early shading of the bent shoot was applied 1 week before the underhook cut and the harvest of one of the shoots. The other treatments started on the day the underhook cut was applied and one of the remaining shoots was harvested. Shading was applied with shading cloth (OLS50; Ludvig Svensson, Hellevoetsluis, The Netherlands), which had a transmissivity of $48 \%$ for $P A R$ and was draped over a frame.

The experiment had a randomized complete block design with two blocks and four plots per block. A plot consisted of a double row with 20 plants. Between the plots were two border plants per row. The experiment was conducted in Oct. 2008.

EXPT. 3: SourCE:SINK RATIO. In this experiment, five treatments were applied to alter the source:sink ratio of the plant: 1) one young shoot per plant (1S); 2) two young shoots per plant $(2 \mathrm{~S})$; 3) two young shoots per plant and shading of the crop (Shade); 4) two young shoots per plant and all leaves removed from the bent canopy (NoL); and 5) minimal assimilate supply, implying three young shoots per plant, shading of the crop, and removal of leaves from the bent canopy (Min).

Additionally, there was a treatment $\mathrm{P}$ to obtain potential growth of the GR1 shoot, as described in Expt. 1. In this treatment, one shoot per plant was growing and the bent canopy consisted of two shoots instead of one. Newly developing shoots in this treatment $\mathrm{P}$ were regularly removed. Shading of the crop was done by rectangular tents consisting of shading cloth (OLS50) on a bamboo frame $1.5 \mathrm{~m}$ above the bent canopy. Transmissivity of the shading cloth was $48 \%$. Growth of the GR shoot was followed as described in Expt. 1, but shoot dimensions were measured only twice. These two measurement days were 2 weeks apart, the first one $1 \mathrm{~d}$ before the treatments were started. Budbreak was recorded $17 \mathrm{~d}$ after initiation of the treatments.

The experiment had a completely randomized design with two plots per treatment. Each plot contained 17 to 20 experimental plants in a double row per treatment with two border plants per row. The experiment was conducted in Apr. and May 2009.

ExPT. 4: Local AND GLOBAL Light. This experiment was designed to test the effect of local and global light. Local light is light reaching a bud, whereas global light refers to light on the crop canopy, affecting the source strength of the crop. The experiment consisted of two subexperiments ( $4 a$ and $4 b$ ). In Expt. 4a, only the amount of local light was varied, whereas in Expt. 4b, both local and global light were varied. Treatments in Expt. 4a were: 1) no local light on buds; and 2) local light on buds. Treatments in Expt. 4b were: 1) normal global light on the crop, no local light on buds; 2) low global light on the crop, no local light on buds; 3) normal global light on the crop, local light on buds; and 4) low global light on the crop, local light on buds.

At the start of the experiment, five shoots were present, which were at least 3 weeks old. One of the shoots of each plant was removed to create the shoot remainder for observation of budbreak, leaving four shoots at least 3 weeks old in each treatment. Local light on the buds of the shoot remainder was supplied by a lighting tube (Fig. 2), which consisted of a nontransparent plastic tube (10 cm long, $4.4 \mathrm{~cm}$ i.d.) in which four LEDs of $0.06 \mathrm{~W}$ each were fixed (LED light set; Gnosjö Konstsmide, Gnosjö, Sweden). The LEDs emitted white light 


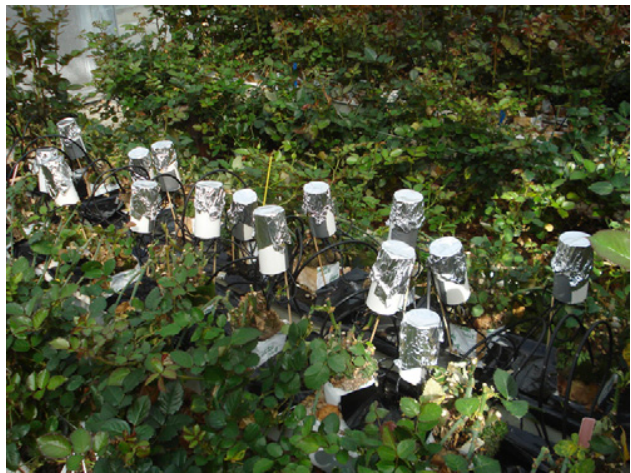

Fig. 2. Lighting tubes. Non-transparent light tubes encapsulating a shoot remainder in rose plants in the experiment on local vs. global light (Expt. 4). Inside the tubes were light-emitting diodes emitting white light.

with peaks in wavelengths $\approx 440$ and $570 \mathrm{~nm}$. The red:far-red ratio inside the tube was 1.16 [wavelengths 655 to $665 \mathrm{~nm}$ for red light and 725 to $735 \mathrm{~nm}$ for far-red light (LI-1800; LI-COR Biosciences, Lincoln, NE)] compared with 0.37 under four shoots in a similar crop. Light intensity inside the tubes was $14.7 \mu \mathrm{mol} \cdot \mathrm{m}^{-2} \cdot \mathrm{s}^{-1}$ [wavelengths 400 to $700 \mathrm{~nm}(\mathrm{LI}-1800)$ ]. The top of the tube was covered with aluminium foil. The lighting tubes encapsulated the shoot remainders. A stick was attached to the tube, and the other end of the stick was placed in the rockwool cubes. LEDs were turned on for $20 \mathrm{~h}$ during Expt. $4 \mathrm{a}$ and continuously turned on during Expt. 4b. Low global light on the crop was achieved by shading the crop. The shading cloth used was the same as in Expt. 3.

Budbreak on the shoot remainders was observed after $12 \mathrm{~d}$. Each experiment had a randomized complete block design. There were three blocks with four plots per block and 18 plants per plot. Four plants in a double row were located between the plots. Expt. 4a was conducted in Mar. 2010 and Expt. 4b in May 2010.

Quantifying SOURCE:Sink Ratios in ExPTS. 1 ANd 3. Stem volume for destructively and non-destructively measured shoots was estimated from the length and diameter measurements of the stem assuming a cylindrical shape of the stem. Data of the destructively harvested shoots were used to derive relationships to transform estimated stem volume into shoot dry weight. A linear relationship was assumed between shoot fresh weight and estimated stem volume. $R^{2}$ was 0.99 in Expt. 1 and 0.98 in Expt. 3, and the residual SEs were 2.44 and $1.98 \mathrm{~g}$ in Expts. 1 and 3, respectively. To convert shoot fresh weight to shoot dry weight, a linear relationship between dry matter content and shoot age was fitted. $R^{2}$ was 0.94 in Expt. 1 and 0.79 in Expt. 3, and the residual SE was 0.012 and 0.015 , respectively.

For the shoots from which stem dimensions were measured non-destructively, these established relationships were used to estimate shoot dry weight at the initial and final measuring dates. Growth of the GR1 shoot was the dry weight increase between the initial and final measurements. Shoot growth of the GR1 shoot in treatment P was assumed to be potential (nonlimiting assimilate supply). Similar to Expt. 1, source:sink ratio in a particular treatment was quantified as the increase in dry weight of the GR1 shoot in this treatment divided by the increase of dry weight of the GR1 shoot in treatment P.

Statistical ANALYSES. For all experiments, the total number of growing buds and number of growing buds per position (upper bud, lower bud, and buds in the basal ring) were calculated per plant and then averaged per plot. In the analysis of the experiment on the role of the bent shoot (Expt. 2), the number of buds was averaged over the three shoot remainders per plant before averaging per plot. Although the number of repetitions (plots) per treatment was only two in Expts. 1, 2, and 3, the high number of plants per plot (nine to 20) ensured that an accurate average per plot was obtained, allowing to detect small treatment differences to be statistically significant. The total number of growing buds per shoot remainder and the number of growing buds per position were analyzed using analysis of variance (ANOVA). The number of growing buds on the upper and lower positions was arcsine-square root transformed to normalize the data. In the experiment on local and global light (Expt. 4), the results of Expts. $4 \mathrm{a}$ and $4 \mathrm{~b}$ were combined with the subexperiments as a random effect. If there was a significant treatment effect, mean separation was done applying Tukey's honestly significant difference test.

Source:sink ratio (Expts. 1 and 3) was calculated per plant and average per plot. The relationship between source:sink ratio and the average number of outgrowing buds per plot was tested by Spearman's rank correlation coefficient.

Timing of budbreak (Expts. 1 and 2) was analyzed using survival analysis (Kleinbaum and Klein, 2005). Survival curves based on growing buds only were compared using Cox' proportional hazards model. Effects of number of young shoots and bud position (Expt. 1) and effects of treatment on the bent shoot, position of the parent shoot, and position of the bud (Expt. 2) on time to budbreak were tested using the log-rank test.

Statistical analyses were done in R 2.12.2 (R Core Development Team, 2011) for regressions on source:sink ratio, correlations, survival analysis) and Genstat (14th edition; VSN International, Hempstead, U.K.) for ANOVA.

\section{Results}

NuMBERS OF BROKEN BUDS. The number of broken buds per shoot remainder increased significantly when fewer young shoots were present [Expt. $2, P<0.001$ (Fig. 3A)]. It did not differ between treatments with three or four young shoots, but the number of growing buds in treatments with zero, one, or two young shoots differed significantly from each other. Differences in total budbreak between plants with different number of young shoots were the result of differences in budbreak in upper buds $(P<0.001)$, lower buds $(P<0.001)$, and buds in the basal ring $(P=0.002)$ (Fig. 3A). In plants with no young shoots, often more than one bud in the ring started growing, whereas more than one growing bud in the ring was rare when young shoots were present. The number of growing buds was positively correlated to the estimated source:sink ratio [Spearman rho 0.83 , $P=0.02$ (Fig. 3B)].

Treatments on the bent shoot (Expt. 2) significantly increased budbreak per shoot remainder $(P=0.046)$, but the effect was small (Fig. 4A). The difference between the highest and lowest number was less than one growing bud. Position of the parent shoot had a strong effect on budbreak: budbreak was significantly higher in the upper parent shoot than in the lower parent shoots $[P<0.001$ (Fig. 4B)]. Higher total budbreak in the upper parent shoot was the result of higher budbreak in all bud positions $[P<0.001$ for all positions (Fig. 4B)].

Treatments aimed at changing the source:sink ratio (Expt. 3) resulted in a slight but significant difference in the total number 

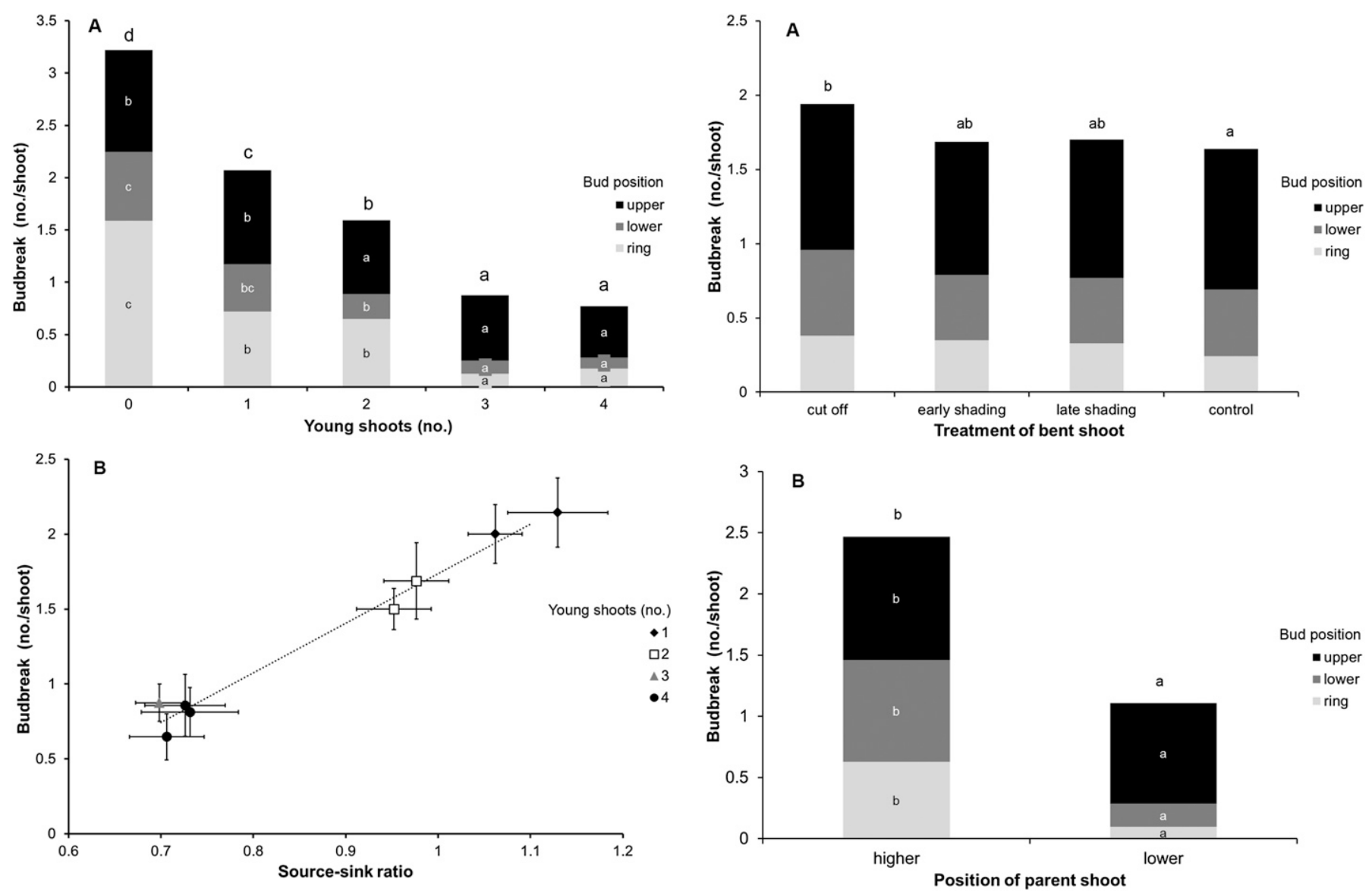

Fig. 3. Budbreak per shoot remainder in cut-rose as affected by different number of young shoots (Expt. 1). (A) Number of growing buds per position (upper buds, lower buds, and buds in the basal ring); different letters refer to significant treatment differences according to Tukey's honestly significant difference test $(P=0.05)$ for total budbreak (above bar) and per bud position (inside bar); (B) budbreak in relation to source:sink ratio, Spearman rho = $0.83, P=0.02$; different symbols refer to plants with different number of young shoots. The ratio between actual and potential growth rate of shoot GR1 was used as a relative indicator for source:sink ratio. Source:sink ratio could not be calculated for treatment without young shoots, because there was no GR1 shoot.

of growing buds $(P=0.018)$. Budbreak was significantly increased when leaves were removed from the canopy compared with a shaded crop, but other treatments did not significantly differ from each other (Fig. 5). The variation in source:sink ratio between the treatments was considerable (Fig. 5), but there was no correlation between source:sink ratio and the number of growing buds when all treatments were considered (Spearman rho 0.04, $P=0.92$ ). However, there was a positive correlation between source:sink ratio and budbreak (Spearman rho $0.89, P=0.03$ ) when only data were considered from the treatments in which the leaves were not removed from bent canopy. In the treatments in which leaves were removed from the bent shoot, Spearman rho was 1 but not significant $(P=0.08)$.

Local light (Expt. 4) affected the total number of growing buds $[P=0.006$ (Fig. 6), interaction $P=0.18]$, whereas the effect of global light was just not significant $(P=0.06)$. Budbreak for the different bud positions was only observed in subexperiment $4 \mathrm{~b}$, but there was no significant effect of local or global light on budbreak in the different positions $(P>0.05)$.

Fig. 4. Budbreak per shoot remainder in the experiment in cut-rose on role of the bent shoot (Expt. 2). (A) Budbreak as affected by shading and removing the bent shoot; letters refer to differences in total budbreak per shoot remainder $(P=0.046)$; differences between bud positions were not significant $(P>0.05)$; budbreak was averaged over one upper and two lower shoot remainders; (B) budbreak as affected by position of the parent shoot; different letters refer to significant differences between parents shoots according to Tukey's honestly significant difference test $(P=0.05)$ for total budbreak (above bar) and budbreak per position (inside bar). Budbreak was averaged over the treatments of the bent shoot (bent shoot cut off, shading of bent shoot 1 week before the other treatments started, shading of bent shoot at start of other treatment, control).

TIMING OF BUDBREAK. The effects of number of young shoots and position of the bud (Expt. 1) on time to budbreak were significant $(P=0.003$ and 0.004 , respectively) but small (Fig. 7A-B). There was no significant interaction between the number of shoots and bud position on time to budbreak $(P=0.11)$. Budbreak was delayed in plants with two, three, or four young shoots compared with budbreak in plants with zero or one young shoot. The upper bud (x1) started to grow first followed first by buds in the ring and then by the lower bud. On average, the time between two successive budbreaks was $2.0 \mathrm{~d}$.

In the experiment on the effect of the bent shoot on budbreak (Expt. 2), there was a delay in budbreak when the bent shoots were shaded $[P=0.03$ (Fig. 8A) ]. Budbreak occurred earlier on the lower parent shoot than on the upper parent shoot $[P<0.001$ (Fig. 8B)]. Budbreak occurred first in the upper bud followed by the lower bud and the buds in the ring started to grow last $[P<$ 0.001 (Fig. 8C)]. Time between budbreak of two successive 


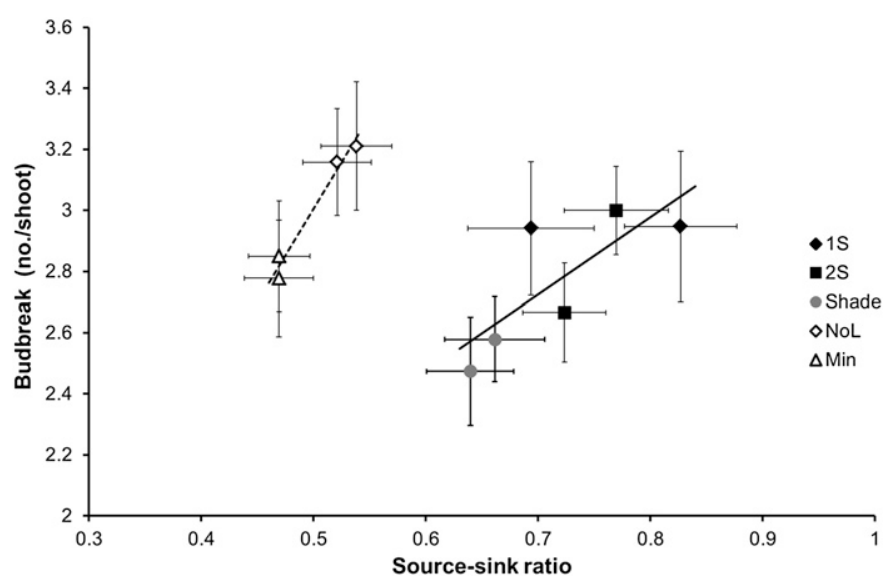

Fig. 5. Budbreak per shoot remainder influenced by different source:sink ratios in cut-rose (Expt. 3). Treatments: $1 \mathrm{~S}=$ one shoot per plant; $2 \mathrm{~S}=$ two shoots per plant; $\mathrm{NoL}=$ no leaves on the bent shoot; Shade = shading of the crop; $\mathrm{Min}=$ minimal assimilate supply: three vertical shoots per plant, no leaves on bent shoot and shading of the crop ( $48 \%$ light transmission). The ratio between actual and potential growth rate of shoot GR1 was used as a relative indicator for source:sink ratio.

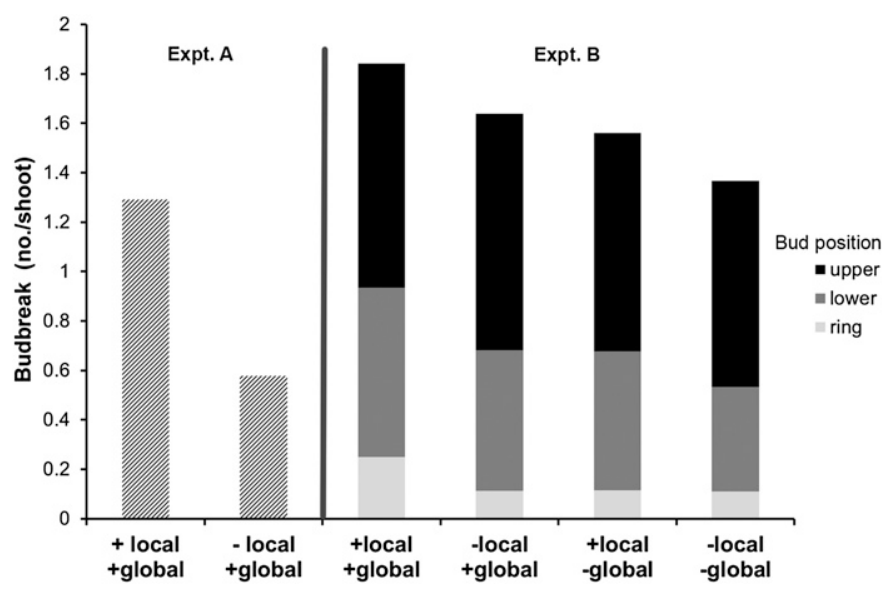

Fig. 6. Effect of local and global light on budbreak per shoot remainder in cutrose (Expt. 4). The experiment consisted of subexperiments A (only local light varied) and B (both local and global light varied). + local = local light applied; - local: no local light applied; + global $=$ global light not reduced; - global $=$ global light reduced by shading. Local light was applied through a tube containing lights on the shoot remainder on which budbreak was observed. Global light was reduced using a shading cloth ( $48 \%$ light transmission) over the crop. Local light significantly affected bud outgrowth $(P=0.006)$, whereas the effect of global light was almost significant $(P=0.06)$.

buds on the upper parent shoot was slightly longer ( $2.5 \mathrm{~d})$ than on the lower parent shoot $(2.3 \mathrm{~d})$.

\section{Discussion}

The aim of this study was to assess the relative importance of four possible hypotheses explaining budbreak on a shoot remainder in a rose crop after harvest of a mature shoot (close to flowering): change in light intensity received by the bud, change in light spectrum received by the bud, changed correlative inhibition, and changed source:sink ratio. In this article, we choose to test the hypotheses by changing the plant architecture or the light environment to alter one or more of these factors. For each
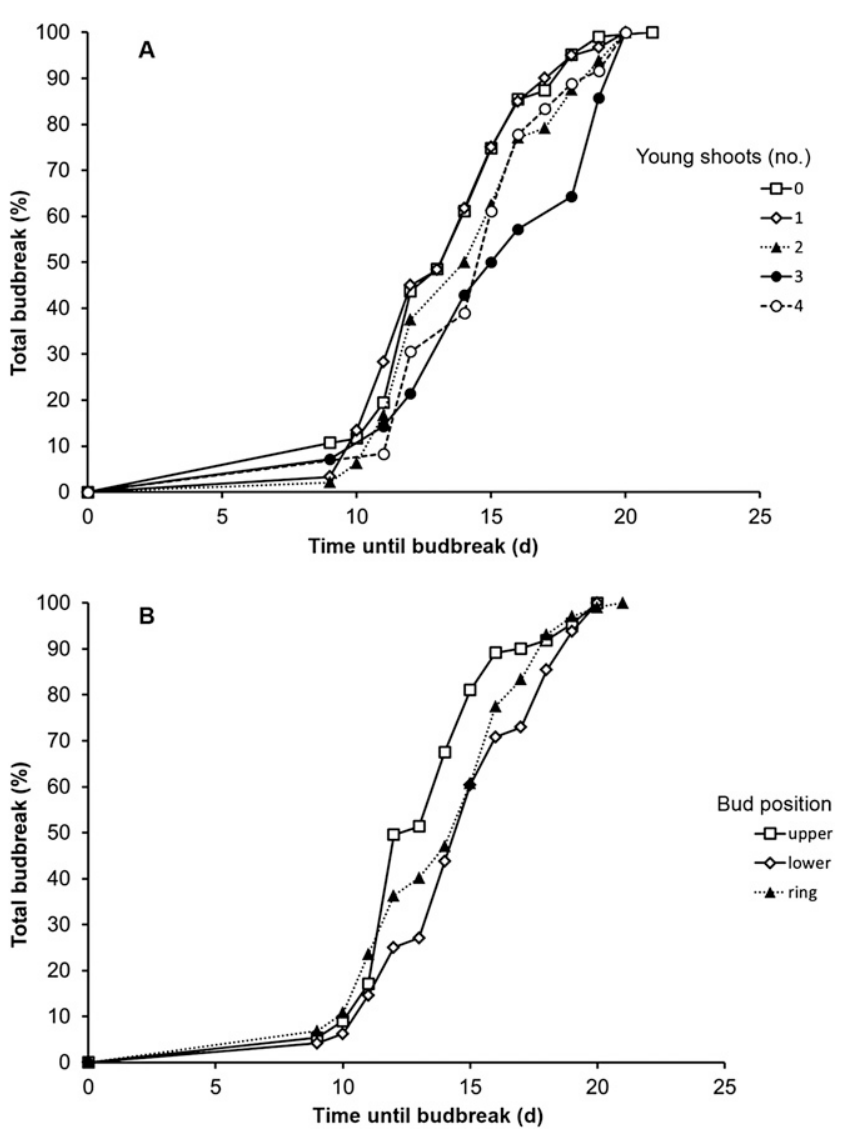

Fig. 7. Timing of budbreak in experiment with different number of young shoots in cut-rose (Expt. 1). Timing of bud outgrowth as affected by (A) number of young shoots $(P=0.003)$ and $(\mathbf{B})$ bud position $(P=0.004)$. Interaction between effect of number of young shoots and bud position was not significant $(P=0.11)$.

experiment, it is discussed whether a hypothesis is confirmed. A summary of the result is given in Table 2 .

LIGHT INTENSITY RECEIVED BY THE BUD. More growing shoots per plant or shading of the crop reduced the light intensity reaching the buds on the shoot remainder studied (although the decrease in light intensity was not quantified). In all cases in which more shoots were present [experiments on different numbers of young shoots (Expt. 1) and on source:sink ratio (Expt. 3)] or shading was present [experiment on source:sink ratio (Expt. 3) and on global and local light (Expt. 4b)], budbreak decreased, although not always significantly. These observations are consistent with the view that reduced exposure of buds to light reduces - or tends to reduce-the fraction budbreak. The presence of the lighting tube (Expt. 4 on local and global light), directly supplying the buds with light, increased budbreak. Shoot remainders higher in the canopy (Expt. 2 on the role of the bent shoot) had more budbreak than shoot remainders lower in the canopy. These shoot remainders higher in the canopy had presumably less foliage above them and as a consequence experienced higher light intensity than shoot remainders lower in the canopy. Thus, the assumption that higher light intensity on the bud increases budbreak was supported by all experiments. Choubane et al. (2012) observed that gibberellin biosynthesis contributes to the positive effect of light on budbreak in roses. 

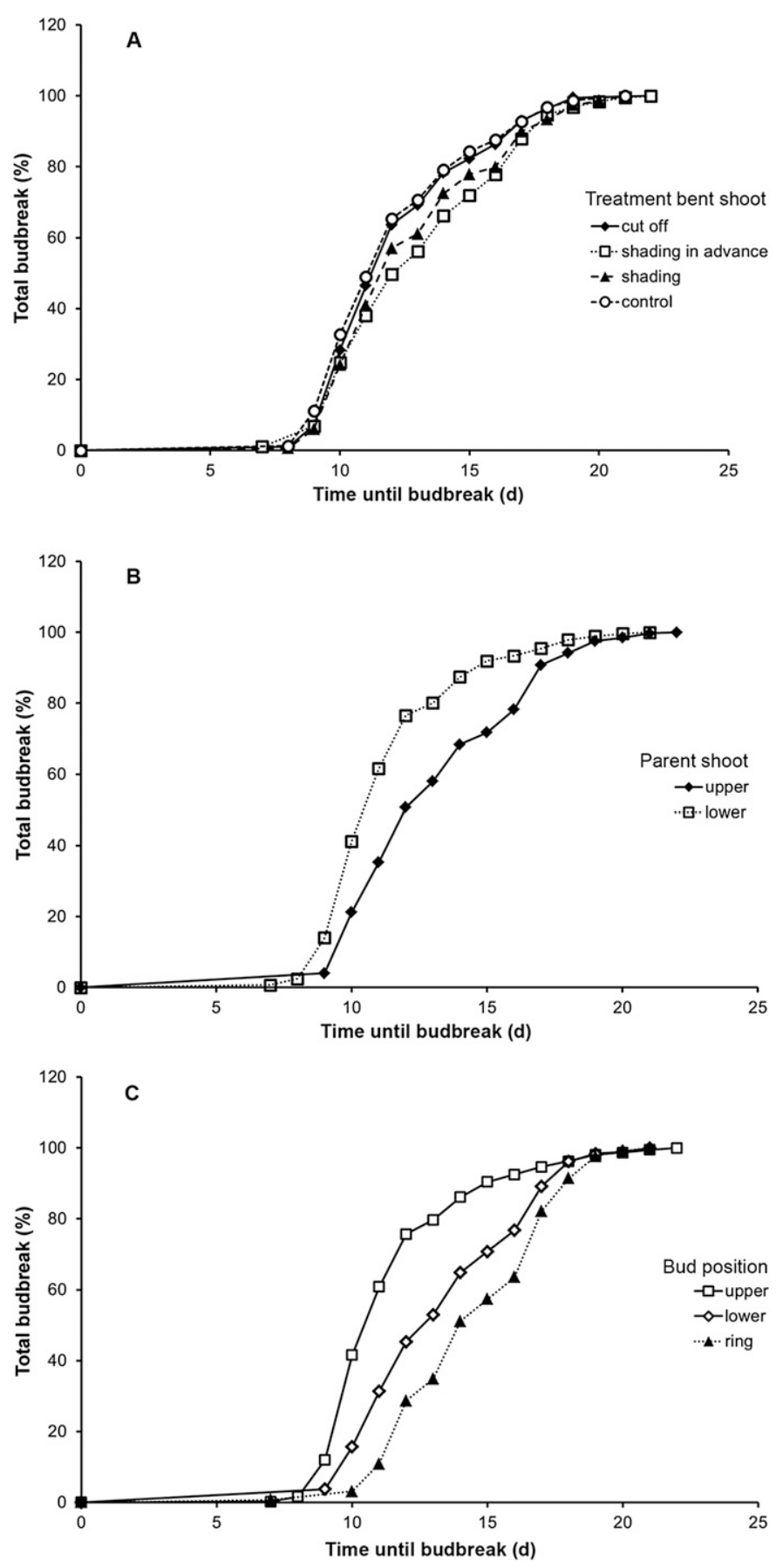

Fig. 8. Timing of budbreak in experiment on role of bent shoot in cut-rose (Expt. 2). Timing of budbreak as affected by (A) treatment on bent shoot $(P=0.03)$, (B) position of the parent shoot $(P<0.001)$, and (C) position of the bud $(P<$ $0.001)$. Three-way and all two-way interactions among treatment of bent shoot, position of the parent shoot, and position of the bud were not significant $(P>0.60$ for all interactions).

Our results are in line with previous results of higher fraction budbreak in rose under higher light intensities (Choubane et al., 2012; Girault et al., 2008; Kosh-Khui and George, 1977). However, the present focus was on light intensity reaching the bud, whereas in other cases, light on the whole canopy was manipulated by applying different levels of assimilation light (Kosh-Khui and George, 1977).
Table 2. Summary of the results of the four experiments in relation to the four hypotheses about variation in budbreak on a shoot remainder in cut-rose.

\begin{tabular}{lccccc}
\hline & & & & & Source: \\
Name of expt. & $\begin{array}{c}\text { Expt. } \\
\text { no. }\end{array}$ & $\begin{array}{c}\text { Light } \\
\text { intensity }\end{array}$ & $\begin{array}{c}\text { Light } \\
\text { spectrum }\end{array}$ & $\begin{array}{c}\text { Correlative } \\
\text { inhibition }\end{array}$ & $\begin{array}{c}\text { sink } \\
\text { ratio }\end{array}$ \\
\hline $\begin{array}{l}\text { Number of young } \\
\text { shoots }\end{array}$ & 1 & $+^{\mathrm{z}}$ & + & + & + \\
Effect of bent shoot & 2 & $\mathrm{NT}$ & $\mathrm{NT}$ & + & - \\
Position parent shoot & 2 & + & + & $\mathrm{NT}$ & $\mathrm{NT}$ \\
Source:sink ratio & 3 & + & $+/-$ & + & $+/-$ \\
Local vs. global light & 4 & + & $+/-$ & NT & $+/-$ \\
\hline
\end{tabular}

$\overline{z_{+}}=$hypothesis supported; $-=$hypothesis contradicted; NT $=$ hypothesis not tested.

LIGHT SPECTRUM RECEIVED BY THE BUD. In SOme of the current experiments, the effects of light intensity and light spectrum received by the bud were confounded. This was the case in the experiment with different numbers of young shoots (Expt. 1) or when the buds were positioned lower in the canopy (Expt. 2). These two experiments could therefore not discriminate between the effects of light intensity and light spectrum. The lighting tube in the experiment on local light (light at bud level, Expt. 4) increased the red:far-red ratio at the bud (1.16 compared with 0.37 under five shoots, see "Materials and Methods") and resulted in a higher level of budbreak. This supports the hypothesis that light spectrum received by the bud affects budbreak. Shading the crop did not alter light spectrum but decreased light intensity. In the experiment on source:sink ratio (Expt. 3) and the experiment on local and global light (Expt. 4), shading had the tendency to decrease budbreak. This might indicate that light spectrum has no effect. Overall, no solid conclusion can be drawn about the effect of light spectrum. Mor and Halevy (1984) and Mor et al. (1980) found a decrease in budbreak when the assimilation light contained a larger proportion of far-red light. In their case, the red:far-red ratio of the light on the whole canopy was altered, whereas in the experiments presented here, the focus was on the light spectrum reaching the buds. Experiments in which light intensity and light spectrum received by the buds are independently varied are needed to elucidate whether light intensity or light spectrum received by the buds is more important in affecting budbreak in a cut-rose crop.

Correlative inhibition. Growing shoots are assumed to inhibit axillary budbreak as a result of correlative inhibition (Zieslin and Halevy, 1976). As such, more shoots should result in less budbreak. This assumption was confirmed in the experiment with different numbers of young shoots (Expt. 1). It was also confirmed in the experiment on the effect of the bent shoot (Expt. 2) and the experiment with different source:sink ratios (Expt. 3), where the bent shoot was removed or its leaves were removed, respectively. Rose growers create a canopy of bent shoots to increase assimilate supply to the vertically growing shoots (De Hoog, 2001) and bending might decrease their correlative inhibitory effect on the rest of the plant (Cline, 1991). As a matter of fact, removing the bent shoot increased budbreak (Fig. 4A), although the effect was small. Also removing all leaves from the bent shoot had a tendency to increase budbreak (Fig. 5). Apparently removal of the assimilates produced in the bent shoot was not important for budbreak and the 
bent shoots still exerted a substantial correlative inhibition of axillary buds. Leaves produce and export auxin (Cambridge and Morris, 1996; Jager et al., 2007), thereby contributing to the correlative inhibition of the shoot.

SoURCE:SINK RATIO. A lower source:sink ratio resulting from more young growing shoots decreased budbreak (Fig. 3B). However, the positive correlation between budbreak and source:sink ratio was not observed in the experiment dedicated to source:sink ratio [Expt. 3 (Fig. 5)] unless only the treatments with the bent shoot intact were considered. On the other hand, shading of the bent shoot or cutting the bent shoot (Expt. 2), which were assumed to decrease assimilate availability, had no negative effect on budbreak. Light intensity on the canopy (global light, which affects the source strength of the plant) affected budbreak, but the effect was small ( 0.27 buds less as a result of shading) and insignificant. From this finding it can be concluded that assimilate supply or source:sink ratio was not the most important factor influencing budbreak. The size (shoot weight and stem length) of mature shoots was lower when the bent shoot was shaded or when the bent shoot was cut off altogether, indicating that these treatments effectively altered the assimilate supply (data not shown). So although the process of budbreak is accompanied by import of sucrose (Henry et al., 2011; Maurel et al., 2004), assimilates needed for this process are apparently sufficiently present in the plant. According to Girault et al. (2010), assimilates used during budbreak were mobilized from the nearby stem, which is consistent with the fact that decreasing assimilate supply from the bent shoot did not affect budbreak. Also in pea (Ferguson and Beveridge, 2009) and Arabidopsis (Su et al., 2011), budbreak could not be explained by differences in assimilate supply and photosynthesis rates, respectively.

Additional consideration on factors afFecting BUDBREAK. In the experiment about the role of the bent shoot (Expt. 2), the ages of the buds differed: buds on the upper shoot remainder were younger than the ones on the lower shoot remainders and the younger buds had a longer time until budbreak (Fig. 8B). This confirms the results of Marcelis-van Acker (1994) that younger buds had a longer time until budbreak, whereas Le Bris et al. (1998) found that bud age was not a major factor in the rate of bud growth.

Buds on the same shoot remainder did not start to grow at the same time, but the uppermost bud started to grow first followed by lower positioned ones (Figs. 7 and 8), and a larger fraction of the upper bud than of the lower positioned buds showed growth (Figs. 3, 4, and 6). More buds growing from the upper bud position than from the lower positioned buds was also reported by Girault et al. (2008), Zieslin et al. (1976), and Zieslin and Halevy (1976). Hence, it might be that budbreak of the upper bud suppresses break of the buds positioned lower on the shoot remainder probably through hormonal processes, of which the knowledge is still incomplete but rapidly expanding (Domalgalska and Leyser, 2011).

The current experiments showed systematic and significant differences in budbreak between treatments within experiments, but there were considerable differences between the experiments in the fraction of budbreak per shoot remainder. The overall fraction of budbreak was high in the experiment with different source:sink ratios (Expt. 3) compared with the other experiments (Fig. 6). The average radiation was highest in this experiment (Table 1), which might explain the high overall level of budbreak. The differences in budbreak between the treatments were much larger in the experiment with different number of young growing shoots (Expt. 1) than in the other experiments. Additionally, budbreak of the lower bud was low in Expt. 1, and it was relatively high in the buds in the ring. The differences in degree and response of budbreak across experiments underlines that there are more determinants of budbreak that have not been revealed in the current study. Clearly, more work needs to be done to be able to predict budbreak in practical situations.

\section{Conclusion}

If a flower shoot in a cut-rose crop is harvested, the buds on the shoot remainder below the cut are released from apical dominance. A variable fraction of the buds on the shoot remainder breaks. Among the factors tested to explain this variation, light intensity reaching the buds appeared to be the most important and consistent factor across experiments, although effects could be confounded with light spectrum. Budbreak was subject to correlative inhibition exerted by other shoots on the plant. Source:sink ratio or assimilate supply is less important in determining budbreak. Growers can use the results to create a more open canopy to increase light intensity on the buds.

\section{Literature Cited}

Barthélémy, D. and Y. Caraglio. 2007. Plant architecture: A dynamic multilevel and comprehensive approach to plant form, structure and ontogeny. Ann. Bot. (Lond.) 99:375-407.

Bredmose, N. 1997. Chronology of three physiological development phases of single-stemmed rose (Rosa hybrida L.) plants in response to increment in light quantum integral. Sci. Hort. 69: 107-115.

Cambridge, A.P. and D.A. Morris. 1996. Transfer of exogenous auxin from the phloem to the polar auxin transport pathway in pea (Pisum sativum L.). Planta 199:583-588.

Choubane, D., A. Rabot, E. Mortreau, J. Legourrierec, T. Péron, F. Foucher, Y. Ahcène, S. Pelleschi-Travier, N. Leduc, L. Hamama, and S. Sakr. 2012. Photocontrol of bud burst involves gibberellin biosynthesis in Rosa sp. J. Plant Physiol. 169:1271-1280.

Cline, M.G. 1991. Apical dominance. Bot. Rev. 57:318-358.

De Hoog, J. 2001. Handbook for modern greenhouse rose cultivation. Applied Plant Research, Aalsmeer, The Netherlands.

Domalgalska, M.A. and O. Leyser. 2011. Signal integration in the control of shoot branching. Nat. Rev. Mol. Cell Biol. 12:211221.

Evers, J.B., J. Vos, B. Andrieu, and P.C. Struik. 2006. Cessation of tillering in spring in relation to light interception and red/far-red ratio. Ann. Bot. (Lond.) 97:649-658.

Ferguson, B.J. and C.A. Beveridge. 2009. Roles for auxin, cytokinin, and strigolactone in regulating shoot branching. Plant Physiol. 149:1929-1944.

Finlayson, S.A., S.R. Krishnareddy, T.H. Kebrom, and J.J. Casal. 2010. Phytochrome regulation of branching in Arabidopsis. Plant Physiol. 152:1914-1927.

Girault, T., F. Abidi, M. Sigogne, S. Pelleschi-Travier, R. Boumaza, S. Sakr, and N. Leduc. 2010. Sugars are under light control during bud burst in Rosa sp. Plant Cell Environ. 33:1339-1350.

Girault, T., V. Bergougnoux, D. Combes, J.D. Viemont, and N. Leduc. 2008. Light controls shoot meristem organogenic activity and leaf primordial growth during bud burst in Rosa sp. Plant Cell Environ. 31:1534-1544.

Henry, C., A. Rabot, M. Laloi, E. Mortreau, M. Sigogne, N. Leduc, R. Lemoine, S. Sakr, A. Vian, and S. Pelleschi-Travier. 2011. Regulation of RhSUC2, a sucrose transporter, is correlated with the 
light control of bud burst in Rosa sp. Plant Cell Environ. 34:17761789.

Jager, C.E., G.M. Symons, N.E. Glancy, J.B. Reid, and J.J. Ross. 2007. Evidence that the mature leaves contribute auxin to the mature tissues of pea (Pisum sativum L.). Planta 226:361-368.

Kawamura, K. and H. Takeda. 2002. Light environment and crown architecture of two temperature Vaccinium species: Inherent growth rules versus degree of plasticity in light response. Can. J. Bot. 80: 1063-1077.

Kleinbaum, D.G. and M. Klein. 2005. Survival analysis: A selflearning text. 2nd Ed. Springer, New York, NY.

Kosh-Khui, M. and R.A.T. George. 1977. Response of glasshouse roses to light conditions. Sci. Hort. 6:223-235.

Le Bris, M., A. Champeroux, P. Bearez, and M.T. Le Page-Degivry. 1998. Basipetal gradient of axillary bud inhibition along a rose (Rosa hybrida L.) stem: Growth potential of primary buds and their two most basal secondary buds as affected by position and age. Ann. Bot. (Lond.) 81:301-309.

Marcelis, L.F.M. 1996. Sink strength as a determinant of dry matter partitioning in the whole plant. J. Expt. Bot. 47:1281-1291.

Marcelis-van Acker, C.A.M. 1994. Development and growth potential of axillary buds in roses as affected by bud age. Ann. Bot. (Lond.) 74:437-443.

Mata, D.A. and J.F. Botto. 2011. Photoperiod, light, and temperature requirements to control plant architecture and flowering time in Salvia exserta. J. Hort. Sci. Biotechnol. 89:408-414.

Maurel, K., G. Berenhauser Leite, M. Bonhomme, A. Guilliot, R. Rageau, G. Pétel, and S. Sakr. 2004. Trophic control of bud break in peach (Prunus persica) trees: A possible role of hexoses. Tree Physiol. 24:579-588.
Mor, Y. and A.H. Halevy. 1979. Translocation of ${ }^{14} \mathrm{C}$-assimilates in roses. I. The effect of the age of the shoot and the location of the source leaf. Physiol. Plant. 45:177-182.

Mor, Y. and A.H. Halevy. 1984. Dual effect of light on flowering and sprouting of rose shoots. Physiol. Plant. 61:119-124.

Mor, Y., A.H. Halevy, and D. Porath. 1980. Characterisation of the light reaction in promoting the mobilizing ability of rose shoot tips. Plant Physiol. 66:996-1000.

Olesen, T., D. Huett, and G. Smith. 2011. The production of flowers, fruit and leafy shoots in pruned macadamia trees. Funct. Plant Biol. 38:327-336.

R Development Core Team. 2011. R: A Language and Environment for Statistical Computing. Vienna, Austria: the R Foundation for Statistical Computing. ISBN: 3-900051-07-0. <http://www.R-project.org/>. Schoellhorn, R.K., J.E. Barrett, and T.A. Nell. 1996. Branching of chrysanthemum cultivars varies with season, temperature, and photosynthetic photon flux. HortScience 31:74-78.

Su, H., S.D. Abernathy, R.H. White, and S.A. Finlayson. 2011. Photosynthetic photon flux density and phytochrome interact to regulate branching in Arabidopsis. Plant Cell Environ. 34:1986-1998.

Zieslin, N. 1981. Plant management of greenhouse roses. Flower cutting procedure. Sci. Hort. 15:179-186.

Zieslin, N., H. Haaze, and A. Halevy. 1976. Components of axillary bud inhibition in rose plants. II. The effect of bud position on degree of inhibition. Bot. Gaz. 137:297-300.

Zieslin, N. and A. Halevy. 1976. Components of axillary bud inhibition in rose plants. I. The effect of different plant parts (correlative inhibition). Bot. Gaz. 137:291-296.

Zieslin, N. and Y. Mor. 1990. Light on roses. A review. Sci. Hort. 43: $1-14$. 